\title{
Cost of care for a geographically determined population of low birthweight infants to age 8-9 years. II. Children with disability
}

\author{
R C Stevenson, P O D Pharoah, C J Stevenson, C J McCabe, R W I Cooke
}

\begin{abstract}
Aim-To determine the cost of health and educational service provision for low birthweight children with a clinical disability. Methods-Cohort study of a geographically defined population in five health districts that comprise the County of Merseyside was undertaken. All children with a clinical disability born in 1980 and 1981 to mothers resident in the County of Merseyside were followed up to age 8-9 years. The cost of care associated with the initial admission to the neonatal special/ intensive care unit and subsequent use of hospital, family practitioner, and special education services was assessed.

Results-There were 52 children with a disability; the disability rate in children of birthweight $\leqslant 2000 \mathrm{~g}$ was estimated at $7 \cdot 7 \%$. Of the total expenditure to age 8-9 years, special education was the largest category $(52 \%)$ and neonatal care accounted for $35 \%$. The disabled children accounted for $38 \%$ of the cost of the whole cohort of 693 disabled and non-disabled children who weighed $\leqslant 2000 \mathrm{~g}$ at birth.

Conclusion-In a cohort of low birthweight children, those who are disabled account for a disproportionate amount of the total expenditure to age 8-9. The cost of long term care for disabled young persons and adults will increasingly dominate the cost of care for the whole cohort of low birthweight children.

(Arch Dis Child 1996; 74: F118-F121)
\end{abstract}

Department of Economics, University of Liverpool

R C Stevenson (Dept of Public Health, University of Liverpool)

Department of Public Health, University of Liverpool

P O D Pharoah

C J Stevenson

Sheffield Centre for Health and Related Research, Sheffield University

C J McCabe

Department of Child Health, Liverpool University

R W I Cooke

Correspondence to: Professor P O D Pharoah Department of Public Health, University of Liverpool, PO Box 147 Liverpool, L69 3BX.

Accepted 5 September 1995

Professional controversy and media coverage have drawn attention to the high cost of neonatal care for low birthweight infants. Neonatal intensive care is highly productive in terms of life-years gained, but low birthweight is associated with a variety of cognitive, motor, and sensory disabilities. Treatment and care for disabled children and adults can be exceptionally expensive in human and financial terms, and these are major costs to be set against the benefits of neonatal intensive care.

This paper reports on the prevalence and cost of disability in a cohort of 944 children weighing $\leqslant 2000 \mathrm{~g}$, born in $1980-81$ to mothers resident on Merseyside. Of these 944 children, $719(76 \%)$ survived to assessment at age 3-4 years; 220 weighed $1500 \mathrm{~g}$ or less, and 499 1501-2000 g. ${ }^{1}$ At age 8-9 the children were followed up to determine their disability status and tested for educational development, motor skills, and behavioural problems. ${ }^{2} 3$

An investigation of the long term cost of disability was beyond the scope of the study, but it is certain that some of the disabled children will require special care for the rest of their lives.

\section{Methods}

The derivation of the study group is shown in fig 1. All children diagnosed as disabled or possibly disabled at age 3-4 were reassessed at age 8-9. The study group consisted of all children assessed as disabled at 8-9.

The children were assessed clinically and classified according to the severity of their disability on a three point scale:

(1) mild disability - for example, myopia, language delay, mild hearing loss, or hyperactivity;

(2) moderate disability - for example, diplegia, hemiplegia, or moderate learning disability (IQ 50-69)

(3) Severe disability - for example, quadriplegia, deafness (loss $\geqslant 70 \mathrm{~dB}$ in either ear), hydrocephalus, uncontrolled epilepsy, or severe learning disability (IQ <50)

\section{COSTING}

Indexing and discounting

All costs are expressed in 1979 prices, discounted at $6 \%$. The estimates may be interpreted as the sum which, invested at $6 \%$ in 1979 , would have provided a flow of income sufficient to pay for the cost of care and education.

\section{Neonatal care}

The costing was based on a detailed study of the Mersey Region Neonatal Intensive Care Unit. ${ }^{4}$ Infants were costed according to the number of days treated in each of three care levels. Surgery (one case) and chromosomal investigations (five cases) were costed separately.

Hospital and family practitioner care to age 8-9 Hospital records were searched to determine all inpatient care and outpatient attendance. Hospital care was priced from costing returns. Family practitioners provided information on consultations and prescriptions which were costed from the 1990 price (indexed and discounted). 
Figure 1 Derivation of study group.

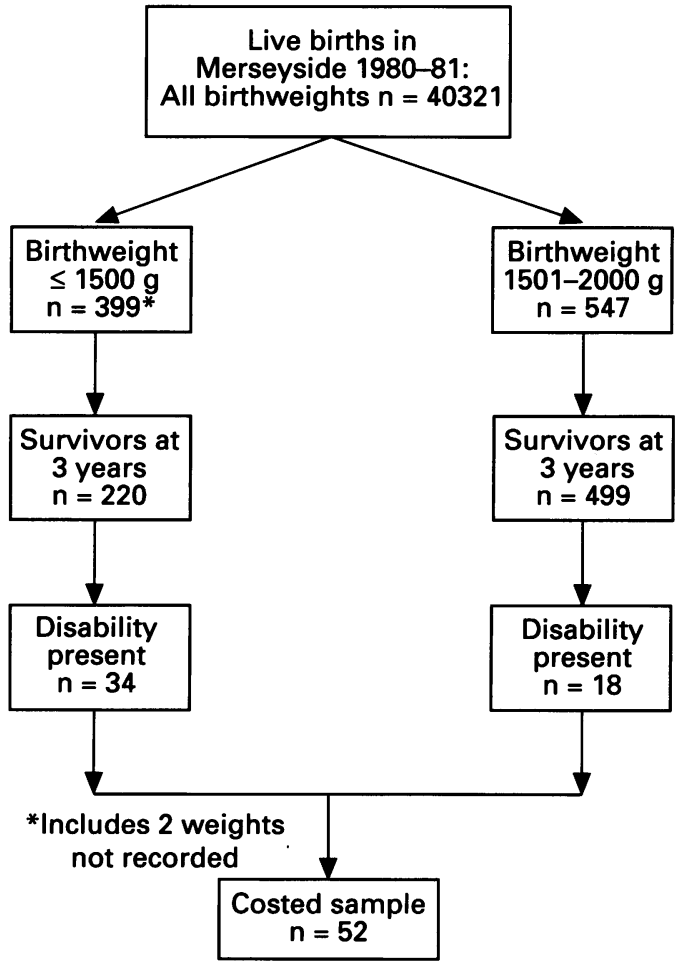

\section{Education}

The Department for Education provided net institutional expenditure per pupil in nursery/ primary and special education for local education authority (LEA) schools. Net institutional expenditure includes wages, salaries, and all recurrent costs, but excludes LEA administration, school meals, transport from home to school and capital costs. Annual expenditure per pupil for charitable special schools was provided by the individual institutions.

\section{Results}

\section{DISABILITY STATUS}

At age 8-9 years there were 52 disabled survivors; nine weighed $\leqslant 1000 \mathrm{~g}$ at birth and 25 weighed 1501-2000 $\mathrm{g}$ at birth. The disability rate is not known with complete certainty because:

- of the initial cohort of disabled and nondisabled low birthweight children, two were untraced, and data were incomplete for 24 who refused assessment or moved. Thirteen of these children weighed $\leqslant 1500 \mathrm{~g}$ at birth;

- of the initial cohort, a $10 \%$ random sample of children in the birthweight group 1501-2000 $\mathrm{g}$ who were without disability were reassessed at age $8-9$. The random sample produced no false negative results, and the $3.6 \%$ disability projected for this birthweight group is thought to be accurate. However, it is not possible to say that all of the $90 \%$ of the group who were not re-assessed are not disabled.

The overall disability rate depends on the outcomes for 12 children who weighed $1500 \mathrm{~g}$ or less at birth, who were not assessed at age 8-9. As one of these children is known to be disabled and two others (resident abroad) are thought to be disabled, the best estimate of the prevalence of disability is $7 \cdot 7 \%$. If all of the unassessed children are disabled, the rate rises to a maximum of $8 \cdot 9 \%$.

\section{TYPE AND SEVERITY OF DISABILITY}

In the study group of 52 disabled children, boys $(n=29)$ outnumber girls $(n=23$, ) but not by a significant margin. All but two had gestational ages of less than 37 weeks. The exceptions were boys of 38 weeks gestation; one has Down's syndrome and the other a $4 p$ chromosome deletion. The 52 children are classified in table 1 by birthweight and by six clinical groups of disability. Children with multiple disabilities are entered once only according to the disability which predominates. The severity of disability is shown by birthweight group in table 2 .

\section{COST OF CARE TO AGE 8-9}

Neonatal care

Total and mean costs by birthweight for three care levels: intensive care, special care, and nursery care are shown in table 3. Wide differences were observed between birthweight groups. On average, infants in the lowest birthweight group cost more than twice as much as those in the middle group, and more than five times as much as those in the higher range. The mean cost per infant was $£ 6926$ (range £719-27 987).

\section{Health service use}

Total and mean cost of health service usage in three categories (hospital inpatient days, outpatient visits, and GP consultations including prescriptions) are shown in table 4 . The mean cost of health service usage was $£ 2584$ (range $£ 1063-3825)$ and again, expenditure seems to be negatively related to birthweight, but the differences between birthweight groups are smaller than for neonatal care.

\section{Special education and institutional care}

At age 8-9 years the children had received at least five years of education. Seven children attended mainstream schools. The remaining 45 attended LEA or charitable special schools, six of which were residential. Total net institutional expenditure, indexed and discounted to 1979 , amounted to $£ 524300$, with a mean of $£ 10083$.

\section{Total cost to age 8-9 years}

The separate cost categories for the 52 children to age 8-9 years are aggregated in table 5 . The mean cost was $£ 19593$. Special education accounted for slightly more than half of the total cost; neonatal intensive care accounted for a further $35 \%$.

PROJECTION OF LONG TERM COST OF EDUCATION AND CARE

The study was not designed to investigate the lifetime costs of disability, but it seems certain 
Table 1 Disabled children classified by predominant disability and birthweight group

\begin{tabular}{lclcl}
\hline Birthweight group (g) & $C P$ & Sensory & Learning & Other \\
\hline 1000 & 5 & 1 & 3 & 0 \\
$1001-1500$ & 15 & 4 & 6 & 0 \\
$1501-2000$ & 7 & 1 & 9 & $1^{\star}$ \\
Total & 27 & 6 & 18 & 1 \\
\hline
\end{tabular}

*This child had a shunted hydrocephalus but no major disability.

Table 2 Disabled children classified by birthweight and severity of disability

\begin{tabular}{lcrrr}
\hline & \multicolumn{2}{c}{ Severity } & Total \\
\cline { 2 - 4 } Birthweight group $(g)$ & 1 & \multicolumn{1}{c}{2} & \multicolumn{1}{c}{3} & \\
\hline 1000 & 3 & 2 & 4 & 9 \\
$1001-1500$ & 6 & 6 & 13 & 25 \\
$1501-2000$ & 4 & 7 & 7 & 18 \\
Total & 13 & 15 & 24 & 52 \\
\hline
\end{tabular}

that beyond the age of 9 , the cost of care and education for disabled children and adults will increasingly dominate the cost for all low birthweight children and adults. Some part of this expenditure can be predicted with certainty. From age 8-9 to school leaving at age 18-19, the disabled children will receive two more years of special primary education and seven years of special secondary education. The cost in 1979 prices discounted at $6 \%$ was estimated at $£ 640795$.

It is also certain that some of the disabled children will receive special education and training beyond the age of 18-19. The provisions of the Further and Higher Education Act 1992 require local councils to take account of the requirements of persons between the ages of 16 and 25 with learning difficulties. Moreover, under some circumstances, councils are empowered to provide boarding accommodation for a person with learning difficulties.

However, the greatest cost will be incurred in looking after severely impaired adults who are likely to require high levels of care throughout their lives. As a rough guide to the magnitude of the long term cost of care, a projection is offered, based on severity of disability and life expectancy estimates. From the data in table 2, children in severity class 3 were assumed to have a life expectancy at birth of 45 years. Children in severity classes 1 and 2 were

Table 3 Total and mean neonatal costs for 52 disabled infants $£ 1979$ discounted at $6 \%$

\begin{tabular}{lrrrrrr}
\hline Birthweight group $(g)$ & \multicolumn{1}{c}{ No } & \multicolumn{1}{c}{ IC } & \multicolumn{1}{c}{ SC } & \multicolumn{1}{c}{ NC } & \multicolumn{1}{c}{ Total } & Mean \\
\hline 1000 & 9 & 63261 & 20286 & 49842 & 133389 & 14821 \\
$1001-1500$ & 25 & 43149 & 37398 & 95779 & 176326 & 7053 \\
$1501-2000$ & 18 & 1908 & 5658 & 42884 & 50450 & 2803 \\
Total & 52 & 108318 & 63342 & 188505 & 360165 & 6926 \\
\hline
\end{tabular}

$\mathrm{IC}=$ intensive care; $\mathrm{SC}=$ special care; $\mathrm{NC}=$ neonatal care.

Table 4 Total and mean cost of health service use for 52 disabled children to age 8-9 £1979 discounted at $6 \%$

\begin{tabular}{lrllrrr}
\hline Birthweight group $(g)$ & No & Inpatient & Outpatient & \multicolumn{1}{c}{ GP } & Total & Mean \\
\hline 1000 & 9 & 16751 & 12558 & 1962 & 31271 & 3475 \\
$1001-1500$ & 25 & 35965 & 30792 & 5384 & 72141 & 2886 \\
$1501-2000$ & 18 & 10257 & 16306 & 4386 & 30949 & 1719 \\
Total & 52 & 62973 & 59656 & 11732 & 134361 & 2584 \\
\hline
\end{tabular}

assumed to have an expectancy of 70 years at birth.

Those in severity category 1 were supposed to require no institutional care. The 24 children in category 3 and the 15 in category 2 were assumed to require institutional care from age 18-19 to death. The cost of care for highly dependent disabled people in a Merseyside home was $£ 24430$ per year (including capital charges) in 1989. If all those with category 2 and 3 disabilities were to receive care in this institution, the lifetime cost, in 1979 prices discounted at $6 \%$, would be $£ 2168852$. Aggregating actual costs to age 8-9 with projected costs from age 8-9 to death, gives total lifetime costs for the $\mathbf{5 2}$ disabled people as $£ 3$ 828473 with a mean of $£ 73624$.

\section{THE COST OF DISABILITY}

Drawing on the results reported separately for non-disabled low birthweight infants and their controls, ${ }^{5}$ the mean cost of healthcare and mainstream education for a control child was $£ 2038$. The mean cost for a non-disabled low birthweight child (which included the cost of neonatal care for non-survivors) was $£ 4197$. These estimates compare with $£ 19593$ per disabled child. To age 8-9 years, the total cost of medical care and education for 693 low birthweight children (641 non-disabled; 52 disabled) was $£ 3709103$. The total cost for the 52 disabled children $(£ 1018826)$ was $38 \%$ of the cost for the whole cohort.

The cost of disability is the extra cost of caring for a disabled person compared with the cost of some other outcome. It might be assumed that in the absence of neonatal intensive care, all disabled infants would have died, in which case all expenditure on care and education would be a cost to set against the benefits of neonatal intensive care. On this assumption, the cost of disability to age $8-9$ is estimated at $£ 1018826$, or $£ 19593$ per disabled child. Much more tentatively, the projected lifetime cost is $£ 3828473$ with a mean of $£ 73624$. This strong assumption, which places an upper bound on the cost of disability, is not wholly unsustainable. Before the introduction of modern methods of neonatal intensive care, some of the mildly disabled would have survived, but many of the severely disabled infants, whose care constitutes a high proportion of the costs, would have died, or been allowed to die.

An alternative basis for comparison might be the cost for a child of normal birthweight. Drawing on results reported separately for the cost of healthcare for control children, ${ }^{5}$ and making allowance for the cost of normal education, the cost of disability to age 8-9 would be the difference between 52 controls and 52

Table 5 Total cost of health care and education for 52 disabled children from birth to age 8-9 years $£ 1979$ discounted $6 \%$

\begin{tabular}{lr}
\hline Neonatal care & $360165(35 \cdot 4 \%)$ \\
Health service use & $134361(13 \cdot 2 \%)$ \\
Special education & $524300(51 \cdot 4 \%)$ \\
Total & $£ 1018826(100 \cdot 0 \%)$ \\
\hline
\end{tabular}


disabled children, which was $£ 250536$ with a mean of $£ 4818$. If control children receive normal education to age 18 , the projected life time cost of disability would be $£ 3718856$ with a mean of $£ 71516$ per disabled person. This figure takes no account of the cost of education beyond the age of 18 for control children and is subject to adjustment according to the probability that a control child may become disabled in later life.

A third measure of the cost of disability is the difference between the cost of care and education for a disabled child and a nondisabled low birthweight child. The mean cost of medical care and normal education to age 8-9 was estimated at $£ 4027^{5}$ compared with $£ 6926$ for a disabled low birthweight child. If it can be assumed that non-disabled low birthweight children will impose no extra cost on the exchequer after age 9 , and will receive mainstream education to age 18 , the lifetime cost of disability would be $£ 3619068$, or $£ 69$ 597 per disabled child. This measure of the cost of disability is defensible because the disabled children were of low birthweight, but its reasonableness depends on whether low birthweight and disability are related, and the direction of causality. If the cause of the disability contributed to premature birth, the alternative to the birth of a disabled child might have been a non-disabled child of normal birthweight.

\section{Discussion}

All costs are discounted and expressed in 1979 prices and are directly comparable between different groups of children, but cannot be translated easily into current values. However, as a rough guide, health service pay and prices have risen by slightly more than three times between 1979 and 1995 . It should also be noted that those results which depend on projections should be interpreted with caution. Long term cost estimates are highly sensitive to the choice of discount rate. All costs are given in 1979 prices discounted at $6 \%$, which is the rate recommended by the Department of Health. However, at lower discount rates, which might be more appropriate if inflation rates remain low as compared with the $1980 \mathrm{~s}$, the present value of future costs will be significantly higher. This would have the effect of increasing the projected cost of disability.

The cost of long term care for the severely disabled was estimated on the assumption that category 2 and 3 disabled adults would receive all their care in residential accommodation. This strong assumption reflects the view that if some disabled children and adults receive part of their care at home, they would require support from the social services, and would impose on their families costs similar in magnitude to the cost of institutional care.

In all other respects, the estimates are conservative. Recent medical advances have increased life expectancy of disabled people, and it is possible, and in some cases certain, that as the children proceed through adulthood they will also require greater than average amounts of medical care which are not included in these estimates. Furthermore, no account has been taken of the considerable private pecuniary and non-pecuniary costs which disabled children impose on families.

However, the main conclusions relate to costs to age 8-9 years and these are based on closely observed data rather than projections. The cost of care for the 52 disabled children accounts for $38 \%$ of the cost for the whole cohort of 693 disabled and non-disabled children. For disabled children, special education rather than neonatal intensive care is the largest cost category in the first nine years of life. Over the lifetime of the cohort, the cost of disability will increasingly dominate the total cost of prematurity according to the actual cost of long term care, and the rate at which it is discounted.

In the past 10 years advances in neonatology have caused more very low birthweight infants to be treated intensively. As a result, mortality has fallen in the lowest birthweight ranges. Even if the disability rate (estimated in this study at $7 \cdot 7 \%$ ) does not increase, the increased prevalence of disability will have important implications for the exchequer in terms of the cost of special education and long term care. The cost of intensive care for low birthweight infants is of the most immediate concern to NHS purchasers, but this study suggests that it is quantitatively relatively unimportant in the longer term.

This study is a costing exercise rather than an evaluation of neonatal intensive care. As such it does not attempt to weigh costs against benefits, but provides previously unavailable information on the cost profiles of different categories of low birthweight infants which may allow others to judge clinical policy in the light of competing demands for scarce resources.

As a prologue to any such appraisal, it should be emphasised that neonatal intensive care is highly productive in terms of the extra life years which it generates and is not specially expensive by comparison with some treatments offered to adults. ${ }^{6}$ However, it is now possible that as evidence accumulates on the long term costs for low birthweight children and adults, this judgment may need to be reappraised.

We are grateful to the Department of Health which funded the study, and to Rita Angelica, Hilary Goodman, and Paul Blackburn for research assistance.

1 Powell TG, Pharoah POD, Cooke RWI. Survival and morbidity in a geographically defined population of low birthweight infants. Lancet 1986; i: 539-43.

2 Pharoah POD, Stevenson CJ, Cooke RWI, Stevenson RC. Clinical and subclinical deficits at 8 years in a geographically defined cohort of low birthweight infants. Arch Dis Child 1994; 70: F264-70.

3 Pharoah POD, Stevenson CJ, Cooke RWI, Stevenson RC. Prevalence of behaviour disorders in low birthweight Prevalence of behaviour disorders in low
infants. Arch Dis Child 1994; 70: F271-4.

4 Stevenson RC, Pharoah POD, Cooke RWI, Sandhu B. Predicting costs and outcomes of neonatal care for very low
Prenson birthweight infants. Public Health 1991; 105: 121-6.

5 Stevenson RC, McCabe CJ, Pharoah POD, Cooke RWI Cost of care for a geographically determined population of low birthweight infants to age 8-9 years. I. Children without disability. Arch Dis Child 1996; 74: F114-7.

6 Royal College of Physicians of London. Medical care of the newborm in England and Wales. London: RCP, 1988. 